\title{
LXXVI. On spade husbandry
}

\section{Mr. Wm. Falla}

To cite this article: Mr. Wm. Falla (1822) LXXVI. On spade husbandry, Philosophical Magazine Series 1, 59:289, 377-383, DOI: 10.1080/14786442208652755

To link to this article: http://dx.doi.org/10.1080/14786442208652755

$$
\text { 曲 Published online: } 27 \text { Jul } 2009 .
$$

Submit your article to this journal 전

LII Article views: 2

Q View related articles $\asymp$ 
Epiglottis, and passing through that channel. At any rate, a ribbon of tape tied lightly round the neck will prevent it.

The stop-cock when required in action is managed as quick as thought.

I am sorry that my avocations prevent an extension of these observations. I shall for some time take leave of the subject of respiration and suspended animation, and content myself with recommending in my pralections the invention I have proposed, stating always the grounds of that recommendation.

I have the honour to be, sir,

May 10, 1822 .

Your obliged and most obedient,

\section{On Spade Husbandry. By Mr. WM. Falla.}

[The following letter from Mr. Falla, detailing the experiments of four successive year's in the cultivation of wheat by the spade, was addressed to Mr. Owen, of Lanark, and is published by him in an appendix to "A Report to the county of Lanark of a plan for relieving public distress, and removing discontent, by giving permanent productive employment to the poor and working classes." We republish it, because the state of agriculture is such at this moment, that it is of the utmost importance to give every possible publicity to all plans calculated to lighten the burdens, or in any respect alleviate the sufferings of the large portion of the population engaged in agricultural pursuits; and none can add so much to the stock of knowledge on this subject, as men like Mr. Falla, who take truth and experience for their guides, and who never cease to prefer facts to theories-and a little practical good, to a great deal of hypothetical advantage.]

D Gateshead, Newcastle: upon-Tyne, Nov. 13, 1820.

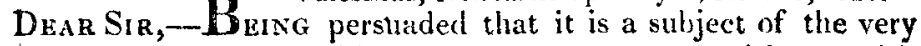
first importance, I readily obey your request to furnish you with the particulars and results of my experiments in the cultivation of land, for the production of wheat, by the spade. It may not be without its use, previously to detail to you the circumstances that brought my attention to this subject. I therefore take the liberty to state, that my principal occupation, for between thirty and forty years past, has been the cultivation of land, chiefly for the raising of trees and seeds for sale; and finding, as I was extending my concerns in that way, about sixteen or eighteen years ago, a difficulty in procuring a sufficient number of men to work the land with the spade, I substituted the plough in working those parts where a considerable quantity of vacant ground happened to lie together, and fancied, that, besides getting through the work with more facility and convenience, which I certainly did, I was doing the work in a manner equal to work done with the spade. The effect of the first use of the plough was not of so much bad consequence as when repeated; the beating of the Vol. 59. No.289. May 1822. $3 \mathrm{~B}$ subsoil 
subsoil by the horses' feet, together with the action of the irots bottom of the plough, not having at first the miserable effect of making the bottom of the worked ground hard and firm, like a turnpike road; the continued successive use of the plough, however, soon showed the bad effect, in the diminished health and vigour of the trees, \&c. Fortunately this observation was inade when men for spade work were easier to be obtained, than at the period when the use of the plough was adopted, and in part then, but entirely since, I have laid it aside in all my nursery operations.

In the use of the spade I produce a depth of well-worked earth of nine to ten inches, which is more than twice that of the plough, as used in the counties of Durham and Northumberlans; and instead of the hardened level bottom, not easily, if at all, penetrable, in our strong clayey subsoils, by either superfluous moisture, or the roots of plants, I obtain a loose broken bottom, conceived to be a particularly favourable circumstance in such soils.

Soon after, or rather during the time that my practice was changing from the use of the plough to that of the spade, I received a letter from a gentleman of great respectability, and accurate observation, in Yorkshire, expressing himself strongly impressed with an opinion, that if garden culture with the spade were introduced into farming, very great addition might be made to the produce of the said land as worked by the plough; and that the full energies of the land will never be called forth till the spade is made to supersede the plough ; asking for my opinion and any observations I might liave made on the subject, detailing, at the same time, the particulars of an experiment in wheat with spade culture, which had been made a good many years before, at Nottingham, the prodnce of which was beyond all example. This information, so strongly corroborating my own observations, confirmed me in my practice of the use of the spade for nursery purposes, and stimulated me to the extension of it, and to the making of experiments of the same kind. The Nottingham experiment having been made with plants of wheat raised upon garden beds, and from thence transplanted juto lines, I began with an adoption of the same mode; I sowed the wheat in beds in the month of August, and transplanted the same in September and October,-the distance of the lines from each other was, in one experiment, nine, and in another twelve inches-placing, in both cases, twelve plants per yard in the lines. These experiments I made two successive years, and the least produce was fifty-two bushels, and the greatest sixty bushels, Winchester, per acre. The quantity of ground under these experiments was half an acre each year, which 1 think may be con- 
sidered a pretty fair quantity for an experiment; perhaps a much smaller one would not be so.

The digging, as at my common nursery price, costs fourpence per rood, of forty-tine square yards (the rood of this country) or thirty-three shillings per acre; the transplanting, fourpence balfpenny per thousand; but there is a great saring of seed, from one to two pecks of wheat producing as many plants as are sufficient to plant an acre, whereas the usual quantity for plough cultivation, sown broadcast, is eight pecks, or two bushels per acre. The following, on these data, is a calculation of the expense of cultivating one aere in this way, supposing the lines nine inches asunder:

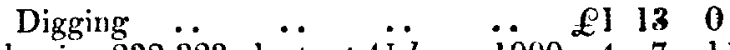

$$
\begin{aligned}
& \text { Transplanting } 232,323 \text { plants at } 4 \frac{1}{2} d \text {. per } 1000 \quad 4 \quad 7 \quad 1 \frac{1}{2}
\end{aligned}
$$

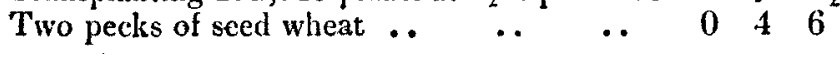

$$
\begin{aligned}
& \text { Total } \quad \ldots \quad \& 6 \quad 4 \quad 7 \frac{\mathrm{r}}{2}
\end{aligned}
$$

During the time of making these experiments, it occurred to me, that probably the increased quantity of wheat, produced in this way, arose more from the deep working of the land by the spade, than from the circumstance of transplantation; and I added to the transplanting experiments, for the two past seasons, others, in which the wheat was suwn both in drills and broadcast, the land in all the cases worked in the same manner by the spade, and the following are the results:

Crop 1819.

No. 1 transpl. from the seed-bed into 6 in. lines, produced $62 \frac{1}{2}$

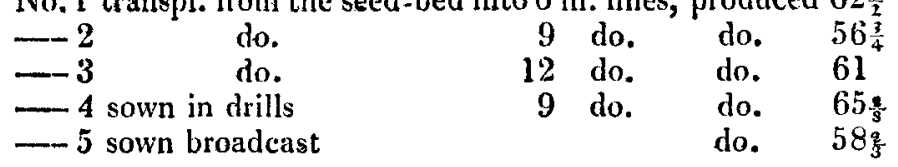

Crop 1820.

No. 1 transpl. from the seed-bed into 6 in. lines, produced $68 \frac{1}{4}$

$\begin{array}{llrlll}-2 & \text { do. } & 9 & \text { do. } & \text { do. } & 68 \frac{1}{4} \\ -3 & 12 & \text { do. } & \text { do. } & 60 \frac{3}{4} \\ -4 & \text { do. } & 9 & \text { do. } & \text { do. } & 73 \frac{\pi}{2} \\ -5 & \text { sown broadcast } & & & \text { do. } & 76 \frac{\pi}{4}\end{array}$

I must here state, that a portion of No. 4 , in the last detailed set of experiments, was laid down by wet, when in flower, and proved very abortive, otherwise I have little doubt that No. 4 (as in the former year) would have exceeded No. 5 in quantity; and a considerable part of the wheat of Nos. 1, 2, and 3, was shaken out by the wind, and destroyed by birds, to the amount probably of five or six bushels per acre.

With relation to denominations of Winchester mcasure, com$3 \mathrm{~B} 2$ 
pared with those of 8 cotland, I have to observe, that the Winchester bushel contains thirty-two quarts, and the quarter eight bushels, also that a boll Linlithgow, or Edinburgh measure, contains, within quite a small fraction, four bushels Winchester.

I have already stated the expense of cultivating by spade work, and transplanting from a seed-bed, in lines nine inches asunder, one acre of wheat; I will now state the expense of one acre in drill, and also broadcast :

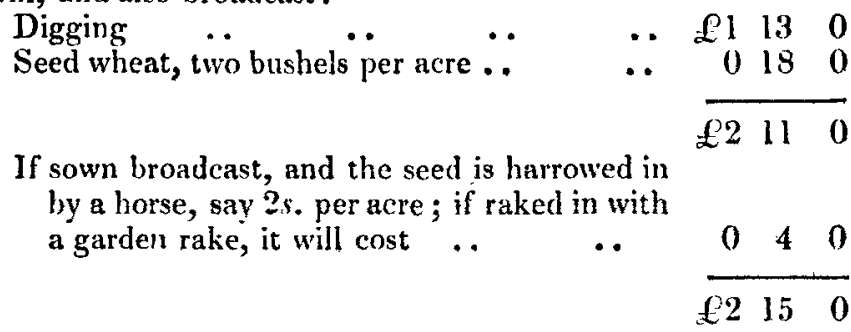

If sown in drills, and the drills made with a garden hoc, it will cost 4 s. per acre more, but a larger saving than that expense will be made in the quantity of seed, compared with the broadcast method.

I now take the liberty to state, what I conceive is the comparative expense of cultivating an acre of land by the plough, and in the first place $I$ have no difficulty in asserting, that one digging, as I have it done (leaving the extra depth out of the question at present) is equal to three ploughings and harrowings; 1 believe I may also state, that the ploughing each time of an acre is calculated to cost $8 s$. and the harrowing $2 s$.-If this is allowed, an acre in this way costs

Three ploughings and harrowings, at 10s. $\& 1 \quad 10 \quad 0$

Seed wheat, two bushels per acre $\ldots$ to 180

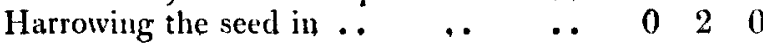

$2210 \quad 0$

Thus it appears that the cultivation of an acre of wheat by the spade, costs only 5 s. more than by the plough. In respect to the comparison of expense between wheat transplanted and sown on land worked by the spade; from the two last years' experiments (the expense of transplanting being of course taken into the question) there can be no doubt that sowing is the butter system, and that the advantage over the plough, is from the deep and otherwise superior working of the land by the spade.

The comparative advantage of produce is now to be stated; the average produce of wheat of the whole island, takiug an average of seven years, is said to be twenty bushels per acre. 
The average of my neighbourhood, I believe, is about twentyfour bushels, but instead of making that a criterion by which to make the comparison, I have to state, that in the autumn of 1819 a good deal of pains was taken to ascertain the quantity of wheat upon a field immediately adjoining my land, and which was what is considered a remarkably fine crop, by which it appeared to be thirty-eight bushels per acre; this was on land, although adjoining, yet of a naturally better quality than mine, and quite as highly manured, worked, in the usual manner of this country, with a two-horse plough, and sown broadcast. By inspection it will be seen, that the average quantity of my drilled and broadcast experiments in 1819 and 1820 , is $68 \frac{\pi}{2}$ bushejs per acre : the value of seed wheat has been assumed to be $9 s$. per bushel, I will however for a whole crop take it lower, say 8 s. per bushel; the comparison in respect to value will then stand thus per acre:

By the spade, $68 \frac{x}{2}$ bushels per acre at $8 s . \quad \begin{array}{llll}227 & 8 & 0\end{array}$

By the plough, 38 bushels per acre at $8 s$. $\quad 15 \quad 4 \quad 0$

The difference is $\mathscr{\& 1 2 \quad 4 0}$

being an advantage gained by the extra expense of $5 s$.

It is of much importance, ou this very interesting subject, that every circunstance connected with the experiments should be known; I therefore state, that the quality of my land on which they were made, although naturally poor, is of that middle texture that will grow the two extremes of turnips and beans; that, at the distance of 10 or 12 miles from Newcastle, it would be let for, at most, $\$ 0 s$. per acre ; that when I got possession of it, there were not above 4 to 6 inches of earth, upon a subsoil of clay; that every year it has been worked, I have brought up to the surface a small quantity, say one inch of the said subsoil, and that $I$ have now a depth of earth of one foot, the whole equal, or more than equal, to the yuality of the 4 to 6 inches upon it, when I first had it;-further, that my experiments for crop 1819 were made after a crop of turnip seed, the land previously manured for the turnips, before the seed was sown, after the rate of 20 tons of stable rlung per acre, no additional dung used for the turnipa, when transplanted, nor for the wheat crop, the plants and seeds respectively, for the different experiments of which wheat crop, were planted and sown at the same time in September. The land upon which the experiments for crop 1820 were made, had previously upon it a three years' crop of transplanted larches, which of course not a little exhausted it; the larches were followed by turnips for seed, a two years' crop, as in the former case, and, as will be allowed, a very exhausting one; this land had an allowance of 20 tous of stable malume per acre, a]pllicd 
applied when the turnip seed was sown, and no more added when they were transplanted: but, considering the state of the land, from the effect of the larches and the turnip seed, it was thought that justice would not be done to the wheat without an application of a smaller portion of the same sôrt of manure, and 1 gave it 10 tons per acre.

I have not yet made any experiments, by spade culture, on oats and barley, but I am intending to make one or more upon each of those grains, and perhaps on beans, the ensuing spring : I am at present digging part of one of my fields for that purpose, the results of which shall be detailed to you.

Being desirous of ascertaining how far, and at what expense, it may be practicable to work land by the spade, by women, boys, girls, and feeble old men, in order, among other reasons, to the employment of paupes sof that description, in which, alas! this country, sonth of the Tweed, superabounds; I have this autumn made an experiment on a piece of laud containing 1728 square yards, by digging or rather trenching by two short spits with girls, and I have the pleasure of saying that the work is bettet done by two such short spits, each about five to six inches deep, the one following the other, than digging is done by men at one full spit or spade full, abont nine to ten inches deep. The common wages I pay to these girls is $10 d$. per day, and they did the work in nineteen days, for one girl, which cost $15 s$. 10d.: -an acre at the same rate, containing 4840 square yards, would cost $2 l, 4 s, 4 d$, this is $11 s .4 d$. per acre more than by men at one spit, but I am satisficd that the superiority of the girls' work is well worth the difference: I may add, that this being the girls' first attempt with spades, I ain persuarled that by further practice they would in a short time do it for the men's price, 33s. The girls work with quite light spades made for the purpose, the best size for which I think to be 93 inches long, 8 inches broad, and weighing, with the light handle, about $4 \frac{1}{2} \mathrm{lbs}$. avoirdupois.

A few months ago I took the likerty of stating to you, that as a parochial concern, for the employmeut of the poor, at present dependent on their respective parishes for relief, your system might be adopted with very great effect ; and oue principal olject, as I have already said, in making the last detailed experiment, was to ascertain how far it is practicable to employ, in the cultivation of the soil, persons who are so dependent on parish relief, of the descriptions of women, boys, girls, and feeble old men, at present doing little more than sitting over the poorhouse fire; the greatest part of whom may, as it is now ascertained, be emploved to great effect in the heaviest manual labour, in the cultivation of the soil; and of course in the easier opcrations 
operations of hoeing, weeding, \&ic. I think I may venture to add, that there need be little doubt entertained that there are few even of such, at present, miserable objects, who would not be able in that way to earn a maintenance, and, were such a measure generally adopted, the poor's rates in England, at present said to amount to eight millions, redueed to perhaps one fourth of that sum. A better arrangement might probably be thought of than what has occurred to me, which is, that the parish, according to the extent of its wants, shall purchase, say from twenty to fifty or more acres of land, build upon it cottages to the necessary extent, employ a proper person to lay out the ground in the best manner for the purpose, see the poor set to work, and that they do the same in a proper manner through all its operations; also that each does a day's work, according to individual ability; and that such as are not able to dig, rake, \&c. be emplnyed in other more easy operations, as the weather and their ability may permit.

Before I conclude, there is one more strong argument in favour of spade husbandry which must be noticed. As far as that mode may be adopted, there will of course be a saving of land for the production of food for man, which is now appropriated to the keeping of horses; and I believe that few persons are aware, that the quantity of land necessary for the keeping of a horse is, as may be very easily made to appear, $4 \frac{1}{2}$ acres; I am meaning a quality of land similar to mine, as already described; which quantity, it may be very clearly made to appear, will afford subsistence for nine persons, on the supposition of a common proportion of men, women, and children, and this under the lnusbandry of the plough : but on the supposition of spade culture, that chuantity of land will produce sufficient sudusistence for more than twelve persons.

Should it be objected that a serions inconvenience may arise from the want of the present supply of mante from horses, the difliculty will be easily obviated by keeping more horned cattle, and by means of an almost religious attention (as in China) to the preservation of perhaps the best and most powerful of all manure, human urine, which at prescnt is, in this island, almost entirely lost.

I am, with sentiments of the greatest respect, dear sir, very sincerely yours,

William Falla.

To Rolert Owen, Esq. 